\title{
Revaluation of Student Failure Reasons Using Non-Additive Methods
}

\author{
Eman Hassan Ouda
}

Received 14/5/2017

Accepted 25/9/2017

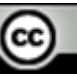

\section{(1)}

This work is licensed under a Creative Commons Attribution 4.0 International License.

\begin{abstract}
:
In this paper, An application of non-additive measures for re-evaluating the degree of importance of some student failure reasons has been discussed. We apply non-additive fuzzy integral model (Sugeno, Shilkret and Choquet) integrals for some expected factors which effect student examination performance for different students' cases.
\end{abstract}

Keywords: Non-additive measures, Sugeno integral, Shilkret integral, Choquet integral.

\section{Introduction:}

The fuzzy set theory was first of all introduced by Lotfi Zadeh in 1965 in his famous paper "Fuzzy Sets", [1]. In classical set theory, crisp sets are defined by characteristic functions whose values are either zero or one, while in the fuzzy set theory the requirement of sharp boundaries got replaced by membership grades which lie between 0 and 1, [2]. The problem of measure additvity has been treated by proposing the non-additive (fuzzy) theory. The non-additive can represent interaction phenomena among elements to be measured. Integrals using Sugeno, Shilkret and Choquet applications and their non-additive measures (generalized ([3], [4]), capacities [5], [6]) is one of the most powerful and flexible functions in the field of aggregation operators and has many applications in different fields of applications such as science, engineering, economics, etc., [7]. These integrals depend on non-additive measure, which are important in mathematics.

Many researchers worked in the field of student performance, such as Biswas (1995) and Gokmen et al (2010) who applied the fuzzy logic to evaluate student achievements ([8],[9]). S.Patil (2012) and others used fuzzy logic for finding the best student based on feedback given by teachers [10]. Sh. Ingoley and J.W. Bakel (2012) proposed a new method for evaluating student performance considering the importance and complexity of examination questions into account using fuzzy inference system (FIS) and fuzzy logic, [11]. J. Azimjonov (2016) studied the parameters effecting the performance of distance learning, [12].

Department of Applied Science, University of Technology, Baghdad, Iraq.

E-mail: emanhasan1966@yahoo.com
Some definitions have been given concerning the non-additive measures and integrals. Section 3 discusses the non-additive model for the performance of some students. In section 4 , we give some case studies with results. In section 5 we finished with some conclusions.

\section{Basic Concepts}

The definitions that are needed in this research of non-additive measures and integrals (Sugeno, Shilkret and Choquet) have been introduced.

\section{Non - Additive Measures:}

The measure is an important tool in applied mathematics and so it is integral. All additive measures are monotonic, in which non-additive measures generalize their additivity replacing additivity by the monotonicity.

\section{Definition 1 [3]}

Let $E$ be a nonempty set and $2^{E}$ be the power set of $E$. A set function $\mu: 2^{E} \rightarrow[0,1]$ is a non additive measure on $(E, \Phi)$, which satisfies:

i- $\mu(\phi)=0$, and $\mu(E)>0$.

ii- $A \subseteq B$ implies $\mu(A) \leq \mu(B)$ for $A, B \in 2^{E}$.

(monotonicity)

For our work, to calculate fuzzy integral, we used $\lambda$ - fuzzy measure.

\section{Definition 2 [13]}

A normalized set function $g_{\lambda}$ defined on $2^{E}$, for $\lambda \in(-1, \infty)$ is called a $\lambda$-fuzzy measure on $E$ if for every pair of disjoint subsets $A$ and $B$ of $E$.

$g_{\lambda}(A \cup B)=g_{\lambda}(A)+g_{\lambda}(B)+\lambda g_{\lambda}(A) g_{\lambda}(B)$

The value of $\lambda$ can be calculated by: 
$1+\lambda=\prod_{i=1}^{n}\left(1+\lambda g_{i}\right), \quad$ where $\lambda \in(-1, \infty)$

\section{Non- Additive Integrals}

Many kinds of non-additive integrals have been used. In this section, we give the definitions that are concerned with our work, such as Sugeno, Shilkret and Choquet integrals with non-additive measures.

Sugeno integral is restricted to functions whose range is $[0,1]$, and normalized non-additive measure, its definition as follows

\section{Definition 3 [3]}

$S I_{\mu}(f)$

$=\int_{n} f \cdot \mu$

$=\bigvee_{i=1}^{n}\left(a_{i} \wedge \mu\left(\left\{E \mid f(E) \geq a_{i}\right\}\right)\right)$

A special type of Sugeno integral is Shilkret integral which is defined as follows (see [11]).

\section{Definition 4 [14]}

$S h_{\mu}(f)=\max _{a \in[0,1]}\left(a_{i \cdot} \mu(\{E \mid f(E) \geq\right.$ $\left.\left.\left.a_{i}\right\}\right)\right) \ldots(3)$

where $\mu: A \rightarrow[0,1]$ is a non-additive measure. This integral has characteristics of comonotone maxitivity and homogeneity.

Also, Choquet integral is one of the types of nonlinear fuzzy integral defined as follows:

\section{Definition 5 [3]}

Let $\mu$ be a non

- additive measure on $E$ and $f$ a function on $E$ with range

$\left\{a_{1}, a_{2}, \ldots, a_{n}\right\}$, where $a_{1} \leq a_{2} \leq \cdots \leq a_{n}$.

The Choquet integral is defined as

(Ch) $\int f d \mu=$

$\sum_{i=1}^{n}\left(a_{i}-a_{i-1}\right) \cdot \mu\left(\left\{E \mid f(E) \geq a_{i}\right\}\right) \ldots(4)$

Some relations concerning Sugeno, Shilkret and

Choquet integrals may be given. These relations are shown below:

(i)Relation between Sugeno integral $(S I)$ and Choquet integral (ChI)

$$
\left|S I_{\mu}(f)-C h I_{\mu}(f)\right| \leq \frac{1}{4} \text {. where } f \text { : }
$$

$E \rightarrow[0,1],(\operatorname{see}[8])$.

(ii) Relation between Shilkret integral $(S h I)$ and

Choquet integral $(C h I)$ is

$\operatorname{ShI}(f) \leq \operatorname{ChI}(f),($ see $[11])$.

\section{A Mathematical Model for Studying of Student's Failure Reasons:}

In this section, an aggregation problem is presented concerning student failure reasons. Nonadditive integrals (Sugeno, Shilkret, and Choquet) with respect to non-additive measures is a useful tool in multicritria decision making, which are used here as aggregation tools.

\section{Case Study}

The student failure is one of the important issues which have been studied by many academic institutes. There are many reasons by which students are failed in any examination systems. Some major reasons for failure have been taken from experts researches.

The most effective factors which have been selected by educational experts with their relative importance may be expressed as follows:

$E_{1}$ : Intelligence Quotient (IQ) or Learning Ability.

$E_{2}$ : Attendance or Regularity.

$E_{3}$ : Subject interesting.

$E_{4}$ : Preparation Ability (using references, internet, dissertation preparation, etc.).

Their standard relative importance degrees are shown in Table 1

Table 1. Relative importance of effective factors on student's grades

\begin{tabular}{llll}
\hline $\boldsymbol{E}_{\boldsymbol{1}}$ & $\boldsymbol{E}_{2}$ & $\boldsymbol{E}_{\mathbf{3}}$ & $\boldsymbol{E}_{\mathbf{4}}$ \\
\hline 0.5 & 0.7 & 0.65 & 0.5 \\
\hline
\end{tabular}

A sample of seven students of first stage (2016-2017) in (Department of Applied SciencesUniversity of Technology) has been chosen for this case. We study student's performance with respect to the previous standard factors; one can predict the realistic of these factors for the possibility of success (or failure). Let $\left\{S_{1}, S_{2}, S_{3}, S_{4}, S_{5}, S_{6}, S_{7}\right\}$ be a set of 7 students for the previous four effective factors $\left\{E_{1}, E_{2}, E_{3}, E_{4}\right\}$. Their values for each student are given in Table 2. These values have been obtained by oral discussion and examination grades with this sample of students.

Table 2. Effecting factors in student's grades

\begin{tabular}{cccccc}
\hline Students & $\boldsymbol{E}_{\boldsymbol{1}}$ & $\boldsymbol{E}_{\mathbf{2}}$ & $\boldsymbol{E}_{\mathbf{3}}$ & $\boldsymbol{E}_{\boldsymbol{4}}$ & $\begin{array}{c}\text { Examination } \\
\text { Grade }\end{array}$ \\
\hline$S_{1}$ & 0.9 & 0.9 & 0.8 & 0.65 & 0.85 \\
$S_{2}$ & 0.15 & 0.35 & 0.55 & 0.25 & 0.35 \\
$S_{3}$ & 0.6 & 0.85 & 0.65 & 0.55 & 0.6 \\
$S_{4}$ & 0.55 & 0.83 & 0.6 & 0.45 & 0.6 \\
$S_{5}$ & 0.75 & 0.98 & 0.75 & 0.35 & 0.75 \\
$S_{6}$ & 0.25 & 0.42 & 0.3 & 0.35 & 0.25 \\
$S_{7}$ & 0.3 & 0.35 & 0.5 & 0.4 & 0.3 \\
\hline
\end{tabular}


As shown in Table 2, student $S_{1}$ has a very good learning ability $E_{1}$ with continuous attendance to lectures $E_{2}$, interesting in learning subjects $E_{3}$ has a very good degree also preparation ability $E_{4}$ is good. For $S_{4}$ and $S_{3}$ we can notice that these factors represent moderate levels, while for $S_{2}, S_{6}$ and $S_{7}$ it represents in total a low level. The fifth column represents actual examination grades obtained by each student.

\section{Construction of $\lambda$-fuzzy measure}

We construct $\lambda$-fuzzy measure as a set of effective factors of the universal set

$E=\left\{E_{1}, E_{2}, E_{3}, E_{4}\right\}$ shown in table 1 .

Then, we have $g_{\lambda}\left(\left\{E_{1}\right\}\right)=0.5, g_{\lambda}\left(\left\{E_{2}\right\}\right)=$ $0.7, g_{\lambda}\left(\left\{E_{3}\right\}\right)=0.65, g_{\lambda}\left(\left\{E_{4}\right\}\right)=0.5$.

Using equation (1), we get $\lambda=-0.9682$.

The values of mutual effect among all the factors $\left\{E_{1}, E_{2}, E_{3}, E_{4}\right\}$ have been computed as shown in Table

Table 3. The mutual effect among the factors

\begin{tabular}{|c|c|c|c|}
\hline $\begin{array}{l}\text { Between } \\
\text { two } \\
\text { factors }\end{array}$ & $\begin{array}{c}\text { Mutual effect } \\
\text { between } \\
\text { factors }\end{array}$ & $\begin{array}{c}\text { Among } \\
\text { three } \\
\text { factors }\end{array}$ & $\begin{array}{c}\text { Mutual } \\
\text { effect among } \\
\text { factors }\end{array}$ \\
\hline$E_{1}, E_{2}$ & 0.8611 & $E_{1}, E_{2}, E$ & 0.9591 \\
\hline$E_{1}, E_{3}$ & 0.8353 & $E_{1}, \stackrel{3}{E_{2}}, E$ & 0.9442 \\
\hline$E_{1}, E_{4}$ & 0.7579 & $\underset{4}{E_{1}, E_{3}, E}$ & 0.9309 \\
\hline$E_{2}, E_{3}$ & 0.9094 & $E_{2}, E_{4}, E$ & 0.9691 \\
\hline$E_{2}, E_{4}$ & 0.8611 & $\begin{array}{c}E_{1}, E_{2}, E \\
{ }_{3}, E_{4}\end{array}$ & 1 \\
\hline$E_{3}, E_{4}$ & 0.8353 & & \\
\hline
\end{tabular}

\section{Calculation of fuzzy integrals}

For student $S_{1}$ $f\left(E_{1}\right)=0.9, f\left(E_{2}\right)=0.9, f\left(E_{3}\right)=0.8, f\left(E_{4}\right)=0.65$, $f\left(E_{4}\right) \leq f\left(E_{3}\right) \leq f\left(E_{2}\right) \leq f\left(E_{1}\right) \quad(0.65 \leq 0.8 \leq 0.9 \leq 0.9)$.

Table 4. Effecting factors for $S_{1}$

\begin{tabular}{|c|c|c|c|c|}
\hline Set & $E_{1}$ & $E_{2}$ & $E_{3}$ & $E_{4}$ \\
\hline$\mu_{f}$ & 0.5 & 0.8611 & 0.9591 & 1 \\
\hline
\end{tabular}
$\mu\left(\left\{E \mid f(E) \geq f\left(E_{\mathrm{i}}\right)\right\}\right)$ :

$\mu_{f}\left(\left\{E_{4}\right\}\right)=\mu\left(\left\{E \mid f(E) \geq f\left(E_{4}\right)\right\}\right)=1$

$\mu_{f}\left(\left\{E_{3}\right\}\right)=\mu\left(\left\{E \quad \mid \quad f(E) \geq \quad f\left(E_{3}\right)\right\}\right)=\mu\{$

$\left.E_{1}, E_{2}, E_{3}\right\}=0.9591$

$\mu_{f}\left(\left\{E_{2}\right\}\right)=\mu\left(\left\{E \mid f(E) \geq f\left(E_{2}\right)\right\}\right)=\mu\left\{E_{1}, E_{2}\right\}=0.8611$

$\mu_{f}\left(\left\{E_{l}\right\}\right)=\mu\left(\left\{E \mid f(E) \geq f\left(E_{1}\right)\right\}\right)=\mu\left\{E_{l}\right\}=0.5$

Now, we apply Sugeno integral (equation (2)) with $a_{i}=f\left(E_{i}\right)$, for this case we obtained $S I_{\mu}(f)=\operatorname{Max}\{\min \{0.9,0.5\}, \quad \min \{0.9,0.8611\}$, $\min \{0.8,0.9591\}, \min \{0.65,1\}\}$ $=\operatorname{Max}\{0.5,0.8611,0.8,0.65\}=0.8611$
By using Shilkret integral (equation (3)), we obtain

$$
\begin{aligned}
S h_{\mu}(f) & =\operatorname{Max}\left\{\begin{array}{l}
(0.9)(0.5),(0.8611)(0.9), \\
(0.9591)(0.8),(0.65)(1)
\end{array}\right\} \\
& =\operatorname{Max}\{0.45,0.775,0.7672,0.65\}=
\end{aligned}
$$

0.755

If we apply Choquet integral (equation (4)) with $a_{i}=f\left(E_{i}\right)$, we obtain

$$
\begin{aligned}
(C h) \int f d \mu= & \sum_{i=1}^{n}\left(a_{i}\right. \\
& \left.-a_{i-1}\right) \cdot \mu\left(\left\{E \mid f(E) \geq a_{i}\right\}\right) \\
(C h) \int f d \mu= & (0.65)(1)+(0.8-0.65)(0.9591) \\
& +(0.9-0.8)(0.8611)+0 \\
= & 0.65+0.1438+0.08611 \\
= & 0.8799
\end{aligned}
$$

For student $S_{2}$

$f\left(E_{1}\right)=0.15, f\left(E_{2}\right)=0.35, f\left(E_{3}\right)=0.55, f\left(E_{4}\right)=$ 0.25 ,

$$
(0.15 \leq 0.25 \leq 0.35 \leq 0.55)
$$

Then we obtained Table 5, using the same method as in $S_{1}$

Table 5. Effecting factors for $S_{\mathbf{2}}$

\begin{tabular}{cllll}
\hline Set & $\boldsymbol{E}_{\boldsymbol{1}}$ & $\boldsymbol{E}_{\mathbf{2}}$ & $\boldsymbol{E}_{\mathbf{3}}$ & $\boldsymbol{E}_{\boldsymbol{4}}$ \\
\hline$\mu_{f}$ & 1 & 0.9094 & 0.65 & 0.9691 \\
\hline
\end{tabular}

If we apply Sugeno integral (equation (2)) with $a_{i}=$ $f(E \quad i)$, for this case we obtain $S I_{\mu}(f)=\operatorname{Max}\{\min \{0.15,1\}, \min \{0.35,0.9094\}$, $\min \{0.55,0.65\}, \min \{0.25,0.9691\}\}$ $=\operatorname{Max}\{0.15,0.35,0.55,0.25\}=0.55$

By using Shilkret integral (equation (3)), we obtain

$S h_{\mu}(f)=\operatorname{Max}\{0.15,0.3182,0.3575,0.2422\}$

$$
=0.3575
$$

Applying Choquet integral (equation (4)) with $a_{i}$ $=f\left(E_{i}\right)$, we obtain

(Ch) $\int f d \mu=(0.15)(1)+(0.1)(0.9691)+$

$(0.1)(0.9094)+(0.2)(0.65)$

$$
\begin{aligned}
& =0.15+0.09691+0.09094+0.13 \\
& =0.4678
\end{aligned}
$$

The other results for students $S_{3}, S_{4}, S_{5}, S_{6}$ and $S_{7}$ are shown in table 6

Table 6. Case studies

\begin{tabular}{ccccc}
\hline Students & $\begin{array}{c}\text { Sugeno } \\
\text { integral }\end{array}$ & $\begin{array}{c}\text { Shilkret } \\
\text { integral }\end{array}$ & $\begin{array}{c}\text { Exoquet } \\
\text { integral }\end{array}$ & $\begin{array}{c}\text { Examatio } \\
\text { ns Grades } \\
\text { (classical } \\
\text { method) }\end{array}$ \\
\hline$S_{1}$ & 0.8611 & 0.7750 & 0.8799 & 0.85 \\
$S_{2}$ & 0.55 & 0.3575 & 0.4678 & 0.35 \\
$S_{3}$ & 0.7 & 0.595 & 0.7833 & 0.6 \\
$S_{4}$ & 0.7 & 0.581 & 0.7523 & 0.6 \\
$S_{5}$ & 0.75 & 0.719 & 0.8946 & 0.75 \\
$S_{6}$ & 0.42 & 0.3013 & 0.3764 & 0.25 \\
$S_{7}$ & 0.5 & 0.4176 & 0.4644 & 0.3 \\
\hline
\end{tabular}


From the previous tables (Table1 to 6), in most cases $E_{1}$ (mental activity, IQ, oral examination performance, class activity, etc.) and $E_{2}$ (students attendance or regularity) have greatest effect on students grades. Also, we can notice that $E_{1}$ or $E_{2}$ coincides with the examination student grade, the same thing can be said for $E_{3}$ (subject interesting). While $E_{4}$ has a small effect on the examination grades. From Table 6, we notice that the results coincides with the relations in section 2.2; therefore, the mathematical model is good expectation of student's grades, and Shilkret integral gives the best results.

\section{Conclusion:}

Mathematical methods have been proposed for re-valuation of examination grades depending on several effective factors suggested by educationalists, these factors can be modified or changed into another factors according to the development of education system. In our work non-additive integrals (Sugeno, Shilkret and Choquet) have been applied for different student's cases. The results were found to be conforming to the real results on the realistic. Shilkret integral was found to be a good tool for evaluating the student performance. This model can be used to investigate new future plans by considering best effective factors, and the capability of non-additive integrals to deal with the efficiency of the education system by improving the most effective factors.

\section{References:}

[1] Zadeh, L. A. 1965. Fuzzy Sets, Information and control, 8(3):338-353.
[2] Dubois, D. J. 1980. Fuzzy Sets and Systems; theory and applications, Vol.144, Academic press.

[3] Wang, Z. and Klir, G. J. 2009. Generalized Measure Theory, Springer.

[4] Torra, V.; Narukawa, Y. and Sugeno, M. 2013. Nonadditive Measures, Theory and applications, Springer, Studies in Fuzziness and Soft Computing.

[5] Choquet, G. 1954. Theory of Capacities, Ann. Inst, Foureier, 5:131-295.

[6] Abbas, J. 2014. Bipolar Choquet Integral of Fuzzy Events, IEEE SSCI Conference on MCDM, Florida, USA, pp.116-123.

[7] Mane, A. M.; Dongale,T. D. and Bapat, M. S. Application of Fuzzy Measure and Fuzzy Integral in Students Failure Decision Making, IOSR Journal of Mathematics 10(6) Ver. III, :47-53 (Nov - Dec. 2014).

[8] Biswas, R. 1995. An Application of Fuzzy Sets in Students' Evaluation, Fuzzy sets and Systems, 74(2):187-194.

[9] G. Gokmen, T. Ç. Akinci, M. Tektaş, N. Onat, G. Kocyigit, and N. Tektaş, 2010. Evaluation of Student Performance in Laboratory Applications Using Fuzzy Logic, Procedia-Social and Behavioral Sciences, 2(2):902-909.

[10] Patil, S.; Mulla, A. and Mudholkar, R. R. 2012.Best student award; A Fuzzy Evaluation Approach, Int. Jor. Comp.Sci.and Comm., 3(1):9-12.

[11] Ingoley, Sh.; Bakel, J. W. 2012.Evaluating Student' Performance Using Fuzzy Logic, International Conference in Recent Trends in Information Technology and Computer Science, ICRTITCS, Int. Jour. Comp. App. , IJCA.

[12] J. Azimjonov, Ih. Selvi, U. Ozbek, 2016. Evaluation of Distance Learning Students Performance Using Fuzzy Logic.

[13] Murofushi, T. and Sugeno, M. 2000. Fuzzy Measures and Fuzzy Integrals: Theory and applications, Physica-Verlag, pp.3-41.

[14] Mihailovic B.; Manzi M. and Dapic P. 2015. The Shilkret-like integral on the symmetric interval, U.P.B. Sci. Bull., Series A, 77(3).

$$
\begin{aligned}
& \text { اعادة تقيم اسباب رسوب الطلبة باستخدام الطرق غير القابلة للاضافة } \\
& \text { ايمان حسن عودة } \\
& \text { الجامعة التكنولوجية، قسم العلوم التطبيقية، بغداد، العراق. }
\end{aligned}
$$

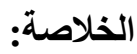

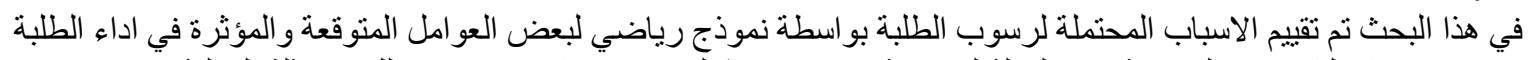

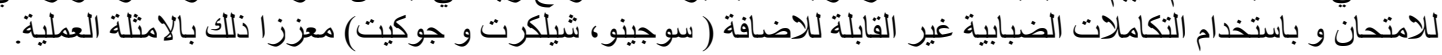

$$
\begin{aligned}
& \text { الكلمات المفتاحية: غير القابلة للأضافة، تكامل سوجينو ، تكامل شيلكرت، تكامل جوكيت . }
\end{aligned}
$$

